\title{
Poor diagnostic values of stool analysis and steatocrit test in detecting exocrine pancreatic insufficiency
}

Ariani Dewi Widodo, ${ }^{1}$ Ina Susianti Timan, ${ }^{2}$ Saptawati Bardosono, ${ }^{3}$ Minarma Siagian, ${ }^{4}$ Widdy Winarta, ${ }^{5}$ Dwi Prasetyo, ${ }^{6}$ Agus Firmansyah $^{7}$

pISSN: 0853-1773 • elSSN: 2252-8083 https://doi.org/10.13181/mji.v28i2.1690 Med J Indones. 2019;28:154-61

Received: January 08, 2017

Accepted: April 22, 2019

Authors' affiliations:

${ }^{1}$ Pediatric Gastrohepatology Division, Harapan Kita Women and Children Hospital, Jakarta, Indonesia, ${ }^{2}$ Department of Clinical Pathology, Faculty of Medicine, Universitas Indonesia, Cipto Mangunkusumo Hospital, Jakarta, Indonesia, ${ }^{3}$ Department of Clinical Nutrition, Faculty of Medicine, Universitas Indonesia, Cipto Mangunkusumo Hospital, Jakarta, Indonesia, ${ }^{4}$ Department of Physiology, Faculty of Medicine, Universitas Indonesia, Jakarta, Indonesia, ${ }^{5}$ Faculty of Medicine, Universitas Indonesia, Jakarta, Indonesia, ${ }^{6}$ Department of Child Health, Faculty of Medicine, Universitas Padjajaran, Hasan Sadikin Hospital, Bandung, Indonesia, ${ }^{7}$ Department of Child Health, Faculty of Medicine, Universitas Indonesia, Cipto Mangunkusumo Hospital, Jakarta, Indonesia

\section{Corresponding author:}

Ariani Dewi Widodo

Gastrohepatology Division, Harapan Kita Women and Children Hospital, Jalan Kapuas No. 10, Cideng, Central Jakarta 10150, DKI Jakarta, Indonesia

Tel/Fax: +62-21-566-8284

E-mail: dr.ariani@gmail.com

\begin{abstract}
BACKGROUND Exocrine pancreatic insufficiency (EPI) is one of the most challenging cases to be diagnosed accurately in Indonesia because of the unavailability of the fecal elastase-1 (FE-1) test, which is the primary indirect diagnostic tool till date. Stool analysis and steatocrit test are feasible alternatives as they can detect nutrient malabsorption, a consistent feature in EPI. Despite the common practice of using both tests, no study has ever been conducted in Indonesia to evaluate their accuracy.
\end{abstract}

METHODS This cross-sectional diagnostic study was conducted in 182 children aged 6-60 months. Study subjects were divided into children with persistent diarrhea (PD), those with malnutrition, and healthy children. Children with PD and malnutrition were selected on the basis of clinical criteria and the WHO z-score. FE-1 test was used as the gold standard to detect EPI. Primary endpoints of this study were sensitivity and specificity of the stool analysis and the steatocrit test. The accuracy of both tests, represented by area under the curve (AUC) values, was also evaluated individually and in combination.

RESULTS Each component of stool analysis and steatocrit test in each subgroup of patients generally had higher specificity than sensitivity. The specificity of both tests among healthy and malnourished children was good ( $\geq 70 \%)$, but among children with PD, the specificity of some components was $<70 \%$. The individual and combined AUC values of both tests in each subgroup of subjects were poor $(<0.7)$.

CONCLUSIONS Stool analysis and steatocrit test cannot be used as alternative methods for FE-1 to detect EPI.

KEYWORDS children, exocrine pancreatic insufficiency, body fat, malabsorption syndromes, pancreatic elastase, pancreatic function tests
The pancreas plays a significant role in the digestive system. A disruption in its function can cause persistent diarrhea (PD), malnutrition, and growth and development problems as nutrients will not be absorbed properly. Based on limited epidemiological data, the prevalence of exocrine pancreatic insufficiency (EPI) has been estimated to range from $8.2-12.9 \%{ }^{1} \mathrm{EPI}$ is characterized by a deficiency of exocrine pancreatic enzymes. The manifestation of EPI varies, but it is primarily similar to maldigestion and malabsorption. ${ }^{2}$ Although EPI, maldigestion, and malabsorption exhibit comparable symptoms, they are in fact different entities. Maldigestion and malabsorption involve a complex process starting from the breakdown of whole food into nutrients, from the mouth to the stomach, to 
the absorption of nutrients in the intestine. In contrast, EPI solely indicates a deficiency of pancreatic enzymes as a part of the larger digestion process. ${ }^{3}$

Tests of exocrine pancreatic function can be conducted directly or indirectly. ${ }^{4}$ The direct secretincholecystokinin (CCK) test is the gold standard but not suitable for children due to its invasive nature. Currently, the most trusted indirect method for evaluating the exocrine pancreatic function is the fecal elastase-1 (FE-1) test. FE-1 produced by acinar cells is highly stable in the digestive tract and does not get degraded while passing through the intestine. Because the test uses a random stool sample, which is noninvasive and convenient, therefore, it can be applied in children as young as 1-month-old. ${ }^{5}$ Löser et $\mathrm{al}^{6}$ found that the sensitivity and the specificity of $\mathrm{FE}-1$ test were as high as $100 \%$ and $93 \%$, respectively, in detecting severe EPI. ${ }^{6}$ Unfortunately, the test is not yet routinely performed in Indonesia even in several national referral laboratories. Moreover, this test uses the enzyme-linked immunosorbent assay (ELISA) method, for which the equipment is not available in laboratories in remote areas of Indonesia.?

Stool analysis and steatocrit test are alternative methods that can be performed to detect maldigestion, one of EPI clinical signs. These tests are convenient, inexpensive, and can be done in remote areas with limited resources as they require only routine reagents such as eosin, lugol, and Sudan III, which are available even in small laboratories. ${ }^{7}$ In particular, the steatocrit test is considered as a good method for diagnosing EPI as it detects the presence of fecal lipid, a prominent parameter of lipid malabsorption and steatorrhea, two common manifestations of EPI. ${ }^{8}$ Unfortunately, the diagnostic value of stool analysis and steatocrit test in detecting impaired exocrine pancreatic function has never been investigated in Indonesia. Therefore, this study was conducted to evaluate whether simple laboratory methods such as stool analysis, steatocrit test, and the combination of both tests can accurately evaluate exocrine pancreatic function. In addition, this study was aimed at determining the cut-off level of steatocrit test in Indonesian children.

\section{METHODS}

A cross-sectional study was designed to evaluate the sensitivity, specificity, and the discriminative capacity of stool analysis and steatocrit test in detecting EPI. FE-1 test was used as the gold standard. Based on a previous study by Widodo et al, ${ }^{9} \mathrm{FE}-1$ values $<307 \mathrm{\mu g} / \mathrm{g}$ of stool were considered as abnormal and an indication of EPI. 9

This study was conducted from January 2015 to July 2016 at the inpatient and outpatient units in five centers, i.e., Department of Child Health FMUI/Cipto Mangunkusumo Hospital, Harapan Kita Women and Children Hospital, Budhi Asih Hospital, Persahabatan Hospital, and Fatmawati Hospital. A total of 182 children aged 6-60 months were included in this study and were further classified into three groups, i.e., children with PD, malnourished children, and healthy (normal) children. Selection of children with PD was based on clinical judgment, while the selection of malnourished children was based on the World Health Organization (WHO) z-score criteria. Healthy children were recruited from 12 preschools and four Integrated Healthy Child Health Center. Children with PD and malnutrition were included in this study because the earlier study had demonstrated that EPI was detected in $26 \%$ and $16 \%$ of children in these two groups, respectively. ${ }^{9}$ The two subgroups of children were selected to evaluate the ability of stool analysis and steatocrit test in determining exocrine pancreatic function in children with EPI in comparison with healthy children. ${ }^{10}$

Patients with EPI known since birth or those who have an inflammatory bowel disease or other types of chronic diarrhea that have been confirmed or treated using antacid, antidiarrheal, antiparasitic, antibiotic, or laxative agents within 2 days before sample collection were excluded. Sample selection from the PD and the malnourished groups was done consecutively. Meanwhile, sample selection from the healthy children group was done using a stratified random sampling method.

Parents who had given an informed consent received a plastic container for stool collection along with specific instructions about how to collect, store, and transport the sample to the laboratory. The random stool sample was collected at home using a plastic layer covering the child's underpant. It was later stored in a medium filled with ice packs and immediately sent to the predetermined laboratory.

Stool analysis was conducted to detect lactose malabsorption (presence of glucose using a glucose strip), fat malabsorption (by the Drumney method using Sudan III), carbohydrate maldigestion 
(presence of amylum using lugol), and protein maldigestion (presence of muscle fibers using $2 \%$ eosin). Other findings included in the analysis were fecal leukocytes and erythrocytes that were examined microscopically. The steatocrit test was conducted using the acid steatocrit method (acetic acid), whereas the FE-1 test, our gold standard, 2,5 was conducted using a standard ELISA method (ScheBo ${ }^{\circledR}$ kit).

Data were analyzed using the Statistical Package for the Social Sciences (SPSS) version 11.5. Descriptive data were presented in texts and tables. Primary endpoints of this study were the sensitivity and the specificity of the stool analysis and the steatocrit test. The accuracy of both tests, represented by area under the curve (AUC) values, was also measured individually and in combination. The sensitivity, the specificity, and the AUC values of both tests were considered as "good" if they were $>70 \%$ and "poor" otherwise." The steatocrit value in the $90^{\text {th }}$ percentile was set as the reference or the cut-off point in determining an abnormal steatocrit value in healthy children aged 6-60 months. This study was granted ethical clearance from the ethics committee
Table 1. Distribution of study subjects and prevalence of EPI

\begin{tabular}{|c|c|}
\hline Subjects & $\mathrm{n}(\%)$ \\
\hline \multicolumn{2}{|c|}{ Age groups (months) } \\
\hline $6-23$ & $80(44)$ \\
\hline $24-60$ & $102(56)$ \\
\hline \multicolumn{2}{|l|}{ Clinical criteria } \\
\hline Healthy & $120(66)$ \\
\hline Malnourished & $31(17)$ \\
\hline With PD & $31(17)$ \\
\hline \multicolumn{2}{|l|}{ Prevalence of EPI } \\
\hline Healthy & $11 / 120(9)$ \\
\hline Malnourished & $5 / 31(16)$ \\
\hline With PD & $8 / 31(26)$ \\
\hline
\end{tabular}

$\mathrm{EPI}=$ exocrine pancreatic insufficiency; $\mathrm{PD}=$ persistent diarrhea

of FMUI-Cipto Mangunkusumo Hospital, No. 111/UN2. F1/ETIK/2015.

\section{RESULTS}

Among the 182 children who participated in this study, 31 children had PD, 31 had moderate or severe malnutrition, and 120 were healthy. To determine the

30

25

\begin{tabular}{ll}
25 \\
\hdashline
\end{tabular}

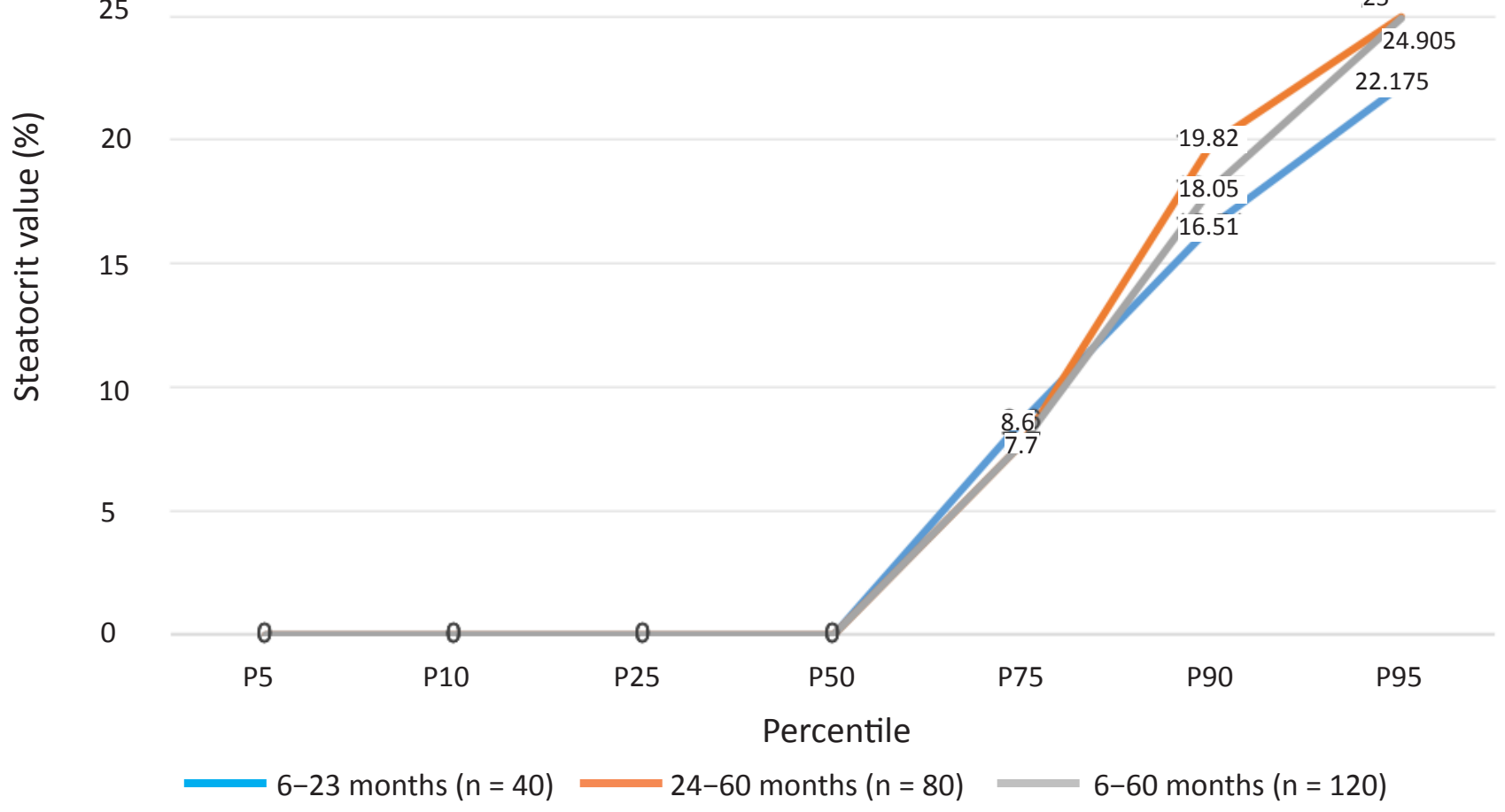

Figure 1. Distribution of fecal steatocrit value in healthy children 
Table 2. Stool analysis and steatocrit diagnostic tests in detecting EPI (healthy children and children with PD and malnutrition)

\begin{tabular}{|c|c|c|c|c|c|c|}
\hline & \multicolumn{6}{|c|}{ FE-1 $(\mu \mathrm{g} / \mathrm{g})(\mathrm{n})^{*}$} \\
\hline & \multicolumn{2}{|c|}{ Healthy } & \multicolumn{2}{|c|}{ Malnourished } & \multicolumn{2}{|c|}{ PD } \\
\hline & $\begin{array}{l}\text { With } \\
\text { EPI }\end{array}$ & $\begin{array}{l}\text { Without } \\
\text { EPI }\end{array}$ & $\begin{array}{l}\text { With } \\
\text { EPI }\end{array}$ & $\begin{array}{l}\text { Without } \\
\text { EPI }\end{array}$ & $\begin{array}{l}\text { With } \\
\text { EPI }\end{array}$ & $\begin{array}{c}\text { Without } \\
\text { EPI }\end{array}$ \\
\hline \multicolumn{7}{|c|}{ Stool analysis } \\
\hline \multicolumn{7}{|c|}{ Lactose malabsorption } \\
\hline Positive & 2 & 10 & 1 & 5 & 1 & 7 \\
\hline Negative & 8 & 100 & 3 & 22 & 7 & 16 \\
\hline \multicolumn{7}{|c|}{ Fat malabsorption } \\
\hline Positive & 0 & 8 & 0 & 3 & 1 & 10 \\
\hline Negative & 10 & 102 & 4 & 24 & 7 & 13 \\
\hline \multicolumn{7}{|c|}{ Carbohydrate maldigestion } \\
\hline Positive & 2 & 23 & 3 & 6 & 2 & 5 \\
\hline Negative & 8 & 87 & 1 & 21 & 6 & 18 \\
\hline \multicolumn{7}{|c|}{ Protein maldigestion } \\
\hline Positive & 5 & 26 & 0 & 8 & 2 & 9 \\
\hline Negative & 5 & 84 & 4 & 19 & 6 & 14 \\
\hline \multicolumn{7}{|l|}{ Leukocyte } \\
\hline$>5$ & 0 & 4 & 0 & 3 & 1 & 8 \\
\hline$<5$ & 10 & 106 & 4 & 24 & 7 & 15 \\
\hline \multicolumn{7}{|l|}{ Erythrocyte } \\
\hline$>3$ & 0 & 2 & 0 & 0 & 3 & 2 \\
\hline$<3$ & 10 & 108 & 4 & 27 & 5 & 21 \\
\hline \multicolumn{7}{|l|}{ Steatocrit } \\
\hline Abnormal & 0 & 12 & 0 & 3 & 2 & 8 \\
\hline Normal & 11 & 97 & 5 & 23 & 6 & 15 \\
\hline
\end{tabular}

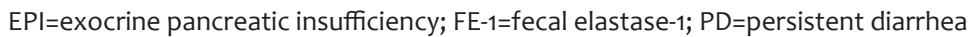
*Positive EPI defined as FE-1 value <307 $\mu \mathrm{g} / \mathrm{g}$ cut-off steatocrit level, the subjects were grouped into the following three age categories: $6-23,24-60$, and 6-60 months (Figure 1).

As shown in Table 1, the proportion of children aged 24-60 months was higher than those aged 6-23 months ( $56 \%$ versus $44 \%$ ). The steatocrit distribution pattern was similar across the three age groups. Therefore, the reference value of steatocrit was determined based on the value trend in the 6-60 months age category. In this study, the normal reference value of fecal steatocrit was $\leq 18 \%$.

Table 2 shows the comparison between the steatocrit test and stool analysis against the FE-1 test as the gold standard in each subgroup. EPI was considered to be "positive" when the FE-1 value was $<307 \mu \mathrm{\mu g} / \mathrm{g} .{ }^{9}$ Among the healthy and malnourished children, some components of stool analysis or steatocrit test showed zero occurences, thus indicating "true positive" results. In addition, in the malnourished children subgroup, none of the subjects had $>3$ erythrocytes in their stool analysis examination.

Table 3 shows the summary of sensitivity, specificity, positive predictive value, and negative predictive value of the steatocrit test and each component of stool analysis. Overall, the results of this study showed that both stool analysis and steatocrit test have higher specificity than sensitivity. The specificity of both tests in healthy and malnourished children was considered to be good (70-100\%), whereas in children with PD, the specificity of some components of the diagnostic tests was poor (57-91\%). Moreover, each component of the diagnostic tests in the PD subgroup showed a lower specificity than that in the other subgroups.

The combined diagnostic test was conducted in two methods. One is the combination of stool analysis components without incorporating the 
Table 3. Sensitivity and specificity of stool analysis and steatocrit test in detecting EPI

\begin{tabular}{|c|c|c|c|}
\hline Endpoints & $\begin{array}{l}\text { Healthy } \\
(n=120)\end{array}$ & $\begin{array}{l}\text { Malnourished } \\
\quad(n=31)\end{array}$ & $\begin{array}{c}P D \\
(n=31)\end{array}$ \\
\hline \multicolumn{4}{|c|}{ Lactose malabsorption } \\
\hline Sensitivity & $17(2-48)$ & $25(1-81)$ & $13(0-53)$ \\
\hline Specificity & $93(86-97)$ & $81(62-94)$ & $69(47-87)$ \\
\hline PPV & $20(6-51)$ & $17(3-57)$ & $13(2-50)$ \\
\hline NPV & 91 (89-93) & $88(80-93)$ & $70(61-77)$ \\
\hline \multicolumn{4}{|c|}{ Fat malabsorption } \\
\hline Sensitivity & $0(0-31)$ & $0(0-60)$ & $13(0-53)$ \\
\hline Specificity & $93(86-97)$ & 89 (71-98) & $57(34-77)$ \\
\hline PPV & $0(0)$ & $0(0)$ & $9(1-40)$ \\
\hline NPV & $91(90-91)$ & $86(84-87)$ & $65(54-74)$ \\
\hline \multicolumn{4}{|c|}{ Carbohydrate maldigestion } \\
\hline Sensitivity & $20(3-56)$ & 75 (19-99) & $25(3-65)$ \\
\hline Specificity & $79(70-86)$ & $78(58-91)$ & $78(56-93)$ \\
\hline PPV & $8(224)$ & $33(17-55)$ & $29(9-63)$ \\
\hline NPV & $92(89-94)$ & 95 (79-99) & $75(66-83)$ \\
\hline \multicolumn{4}{|c|}{ Protein maldigestion } \\
\hline Sensitivity & $50(19-81)$ & $0(0-60)$ & $25(3-65)$ \\
\hline Specificity & $76(67-84)$ & $70(50-86)$ & $61(39-80)$ \\
\hline PPV & $16(9-28)$ & $0(0)$ & $18(6-45)$ \\
\hline NPV & $94(90-97)$ & $83(79-86)$ & $70(58-80)$ \\
\hline \multicolumn{4}{|c|}{ Fecal leukocyte } \\
\hline Sensitivity & $0(0-31)$ & $0(0-60)$ & $13(0-53)$ \\
\hline Specificity & 96 (91-99) & 89 (71-98) & $65(43-84)$ \\
\hline PPV & $0(0)$ & $0(0)$ & $11(2-46)$ \\
\hline NPV & $91(91-92)$ & $86(84-87)$ & $68(59-76)$ \\
\hline \multicolumn{4}{|c|}{ Fecal erythrocyte } \\
\hline Sensitivity & $0(0-31)$ & $0(0-60)$ & $38(9-76)$ \\
\hline Specificity & 98 (94-99) & $100(87-100)$ & 91 (72-99) \\
\hline PPV & $0(0)$ & $0(0)$ & $60(23-88)$ \\
\hline NPV & $92(91-92)$ & 87 (87-87) & $81(71-88)$ \\
\hline \multicolumn{4}{|c|}{ Steatocrit test } \\
\hline Sensitivity & $0(0-28)$ & $0(0-52)$ & $25(3-65)$ \\
\hline Specificity & $89(82-94)$ & $88(70-98)$ & $65(43-84)$ \\
\hline PPV & $0(0)$ & $0(0)$ & $65(43-84)$ \\
\hline NPV & 89 (89-90) & $82(80-84)$ & $71(60-80)$ \\
\hline
\end{tabular}

EPI=exocrine pancreatic insufficiency; $P D=$ =persistent diarrhea; $P P V=$ positive predictive value; $N P V=$ negative predictive value All data are in $\%$ and presented with $95 \%$ confidence intervals $(\mathrm{Cl})$

steatocrit test, and the other is the combination of all components of stool analysis and steatocrit test. The AUC values obtained from this process are presented in Table 4. All AUC values were
$<70 \%$, which is the minimum acceptable value for a test to be considered as good, consistent with the receiver operating characteristic (ROC) curves of all sample subgroups (Figure $2 \mathrm{a}-\mathrm{c}$ ) that are close 
Table 4. AUC values of diagnostic tests in detecting EPI in each subgroup of subjects

\begin{tabular}{lccc}
\hline Tests & $\begin{array}{c}\text { Healthy } \\
(\mathrm{n}=120)\end{array}$ & $\begin{array}{c}\text { Malnourished } \\
(\mathrm{n}=31)\end{array}$ & $\begin{array}{c}\text { PD } \\
(\mathrm{n}=31)\end{array}$ \\
\hline Stool analysis & $58.8(42.2-75.4)$ & $59.2(33.1-85.3)$ & $37.8(13.6-62)$ \\
\hline Lactose malabsorption & $53.7(35.7-71.7)$ & $62.3(33.1-91.5)$ & $41.0(19-63.1)$ \\
\hline Fat malabsorption & $46.3(30-62.6)$ & $44.2(18.3-70.2)$ & $42.9(20.1-65.7)$ \\
\hline Carbohydrate maldigestion & $52.3(34.7-69.9)$ & $68.5(41.2-95.8)$ & $51.6(27.9-75.4)$ \\
\hline Protein maldigestion & $58.8(41-76.6)$ & $34.6(12.4-56.8)$ & $34.5(13.7-55.3)$ \\
\hline Fecal leukocyte & $48.1(31.4-64.9)$ & $44.2(18.3-70.2)$ & $38.9(17.2-60.5)$ \\
\hline Fecal erythrocyte & $49.1(32-66.1)$ & $50.0(21.9-78.1)$ & $56.0(31.7-80.2)$ \\
\hline Steatocrit & $44.4(28.7-60.2)$ & $44.2(18.3-70.2)$ & $45.1(22.1-68.1)$ \\
\hline Stool analysis + steatocrit & $56.9(40.2-73.7)$ & $59.2(33.1-85.3)$ & $37.8(13.6-62)$ \\
\hline
\end{tabular}

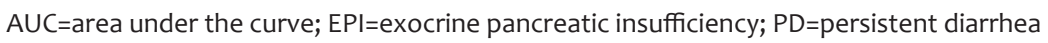
All data are in $\%$ and presented with $95 \%$ confidence intervals (CI)

to the reference line. This finding suggests that the steatocrit test and the stool analysis are inaccurate in detecting EPI in this study sample.

\section{DISCUSSION}

The stool analysis and the steatocrit test have been commonly used by several pediatricians in Indonesia to evaluate a suspected EPI case as these tests are more affordable and widely available than the gold standard, the FE-1 test. This study was aimed at evaluating the diagnostic ability of both tests by comparing them with the FE-1 test.

In this study, both the stool analysis and the steatocrit test showed high specificity and high negative predictive values but low sensitivity and low positive predictive values in detecting EPI, especially in otherwise healthy and malnourished children.

This results contradict those of a previous study reported by Tardelli et al, ${ }^{12}$ who found a considerably high sensitivity (95.7\%; $95 \% \mathrm{Cl}=87.3-100$ ) but low specificity (50\%; $95 \% \mathrm{Cl}=10-90$ ) of the steatocrit test, using the FE-1 test as the gold standard. These different results may be explained by the different type of subjects enrolled in both studies. This study enrolled otherwise healthy children, malnourished children, and children with PD, whereas the study by Tardelli et $\mathrm{al}^{12}$ included children with cystic fibrosis, a prevalent hereditary disorder among Caucasians but extremely rare among Asians. In cystic fibrosis, a genetic abnormality ensues and causes systemic malfunction of exocrine glands, including the pancreas. Subjects with cystic fibrosis will naturally exhibit more apparent clinical characteristics accompanied by low pancreatic enzyme levels, which more likely lead to positive steatocrit test results simultaneously with low elastase levels.

In contrast, individuals with malnutrition and PD, as in this study, generally suffer from villous atrophy that reduces the secretion of CCK and subsequently impairs enzyme production, typically causing a low FE-1 level. ${ }^{13,14}$ However, there might be some subjects who had not experienced PD or malnutrition long enough for the atrophy to impair digestive enzyme secretion, which could probably cause a low sensitivity (true positive rate) of the stool analysis and the steatocrit test as in this study. Low sensitivity also implies that a test is likely to generate a false-positive result. In this study, intestinal villous atrophy in subjects with malnutrition and PD also impairs food digestion, which later manifests as symptoms of maldigestion and malabsorption.

These malabsorption symptoms, which are related to the false-positive result, could also be caused by chronic infections and inflammation, as in patients with PD. Among the three subject groups investigated in this study, the specificity of all components of the stool analysis and the steatocrit test was the lowest in the PD group, suggesting that these tests are more likely to generate higher false-positive results, and therefore less able to detect EPI. Malabsorption that occurs due to intestinal villous atrophy or PD causes the stool composition to be similar to that in EPI.

Genetic differences may also influence the contradicting steatocrit values observed in this study and the study by Tardelli et $\mathrm{al}^{12}$ as both studies 


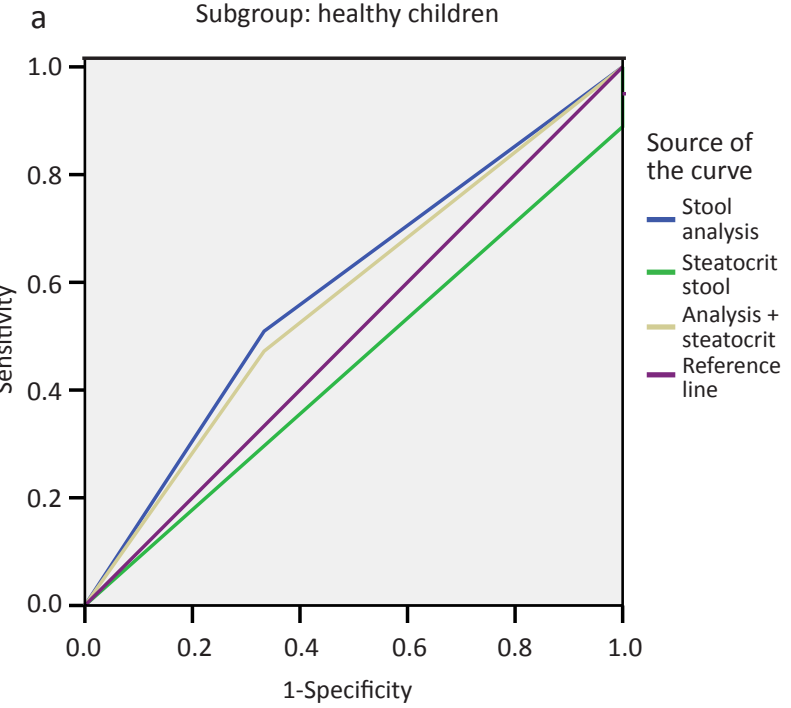

b Subgroup: malnourished children

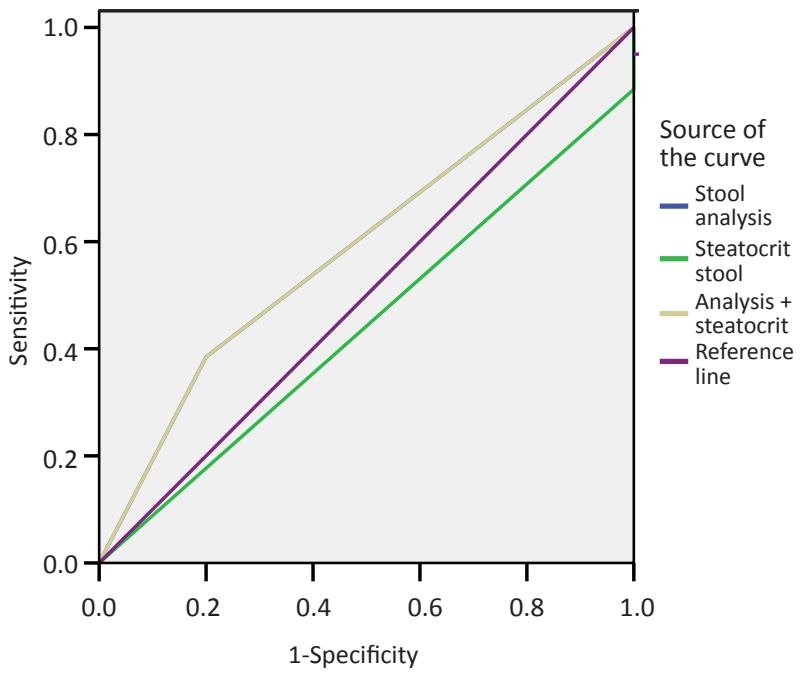

C Subgroup: PD

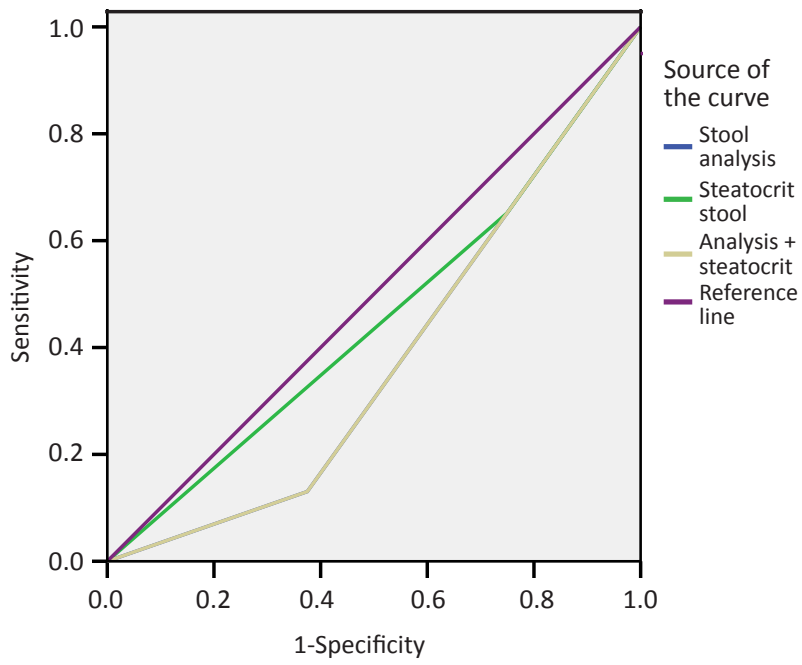

Figure 2. ROC curves of stool analysis only, steatocrit only, and combination of both tests in (a) healthy children, (b) malnourished children, and (c) children with PD. ROC=receiver operating characteristic; $\mathrm{PD}=$ persistent diarrhea involved patients with an extremely different racial background. The fact that the reference of FE-1 level among Indonesian children is higher than the reference level accepted globally supports this explanation. ${ }^{6,15}$ Girish et al $^{16}$ found that steatocrit inversely correlated with $\mathrm{FE}-1$, which implies that if the steatocrit test revealed a high fecal fat level, the level of FE-1 would be low. This finding supports this study that demonstrated high specificity across all subgroups, suggesting that a higher steatocrit level may reflect a more severe EPI.

Stool analysis was also conducted in this study, which demonstrated good specificity. Unfortunately, we were not able to find any literature in Indonesia or outside discussing about the diagnostic value of stool analysis compared with the FE- 1 test. The limited number of studies comparing stool analysis with the $\mathrm{FE}-1$ test may be related to the availability of the FE-1 test as a routine examination in most parts of the world and that stool analysis is not required anymore. Nevertheless, this study has demonstrated that the specificity of each component of stool analysis was very good, suggesting that the test could be used to exclude EPI.

The AUC value of the steatocrit test in this study was approximately 0.4 , in contrast to the 0.728 AUC value obtained by Tardelli et $\mathrm{al}^{12}$ in their study. The study subjects' characteristics as mentioned above could be one of the reasons why the AUC value of the steatocrit test was lower than the result obtained by Tardelli et al. ${ }^{12}$ Another possibility is that steatocrit alone is simply not sufficient to replace the role of FE-1 in diagnosing EPI. Therefore, stool analysis and steatocrit test combined as a single diagnostic entity was also conducted to evaluate whether the AUC value would increase. Unfortunately, the result showed the same low value. Furthermore, the AUC values obtained from each variable and from the result of the combination analysis were $<0.7$. These diagnostic tests were thus categorized as poor with low discriminative capacity for determining the presence of EPI in children.

Despite the low sensitivity and discriminative capacity of the steatocrit test, it can still be used to some extent to diagnose EPI. Amann et $\mathrm{al}^{17}$ and Tran et $\mathrm{al}^{18}$ found that the acid steatocrit test can be performed accurately on random spot stools and predicts the fecal fat concentration well. It can serve as a surrogate marker of $\mathrm{EPI}$, in which a positive 
result should lead a physician to perform a further confirmatory test, such as FE-1. The other application of the steatocrit test in EPI cases, as mentioned by Hammer, is the evaluation of the effectiveness of pancreatic enzyme therapy. ${ }^{19}$

The stool analysis and the steatocrit tests have long been used as an initial set of examinations, if not the only examinations, to diagnose EPI in resourcelimited areas as they are affordable and easy to use, given the unavailability of the FE-1 test in such areas. In situations where there is no other option, the use of these tests may still be acceptable considering their high specificity. Physicians should combine positive results of the stool analysis and the steatocrit test with suggestive signs and symptoms when making a working diagnosis of EPI and further evaluations later. However, this substandard situation can hamper patient care, and therefore, we strongly recommend a policy change to the Ministry of Health and hospital administrations to provide the $\mathrm{FE}-1$ test in all diagnostic facilities across the country.

There are several limitations in this study. A sampling bias may occur due to the different characteristics of the sampling sites from where the subjects were recruited. Children with persistent diarrhea were recruited from hospitals, whereas healthy children were selected from the general population. Furthermore, malnourished children were recruited from both hospitals and general population. The variability of nutritional status among malnourished children was also high primarily because the selection did not differentiate between moderate and severe malnutrition.

As EPI causes various maldigestion and malabsorption of nutrient, further studies should focus on evaluating other maldigestion- or malabsorptionrelated tests, such as the hydrogen breath test or its combination with the steatocrit test and stool analysis, instead of the FE-1 test.

\section{Conflict of Interest}

The authors affirm no conflict of interest in this study.

\section{Acknowledgment}

We would like to express this gratitude to the clinical pathology staff of Cipto Mangunkusumo Hospital, staff of Prodia Wirahusada Laboratory, and colleagues from each hospital from which we recruited this subjects. Special thanks to Dr. Ivan R. Widjaja, SpA and Utami Susilowati for data analysis and also Dr. Safira for subject follow-ups.

\section{Funding Sources}

This study was funded by the Indonesian Danone Institute Foundation.

\section{REFERENCES}

1. Rothenbacher D, Low M, Hardt PD, Klor H, Ziegler H, Brenner H. Prevalence and determinants of exocrine pancreatic insufficiency among older adults: results of a population-based study. Scand $J$ Gastroenterol. 2005;40:697-704.

2. Struyvenberg MR, Martin CR, Freedman SD. Practical guide to exocrine pancreatic insufficiency - breaking the myths. BMC Medicine. 2017;15:29.

3. Keller J, Layer P. The pathophysiology of malabsorption. Viszeralmedizin.2014;30(3):150-4.

4. Lindkvist B. Diagnosis and treatment of pancreatic exocrine insufficiency. World J Gastroenterol. 2013;19:7258-66.

5. Lüth S, Teyssen S, Forssmann K, Kölbel C, Krummenauer F, Singer MV. Fecal elastase-1 determination: 'gold standard' of indirect pancreatic function tests? Scand J Gastroenterol. 2001;36:1029-9.

6. Löser C, Möllgaard A, Fölsch UR. Faecal elastase 1: a novel, highly sensitive, and specific tubeless pancreatic function test. Gut. 1996;39:580-6.

7. Ministry of Health Republic of Indonesia. Management of community health center laboratory. Ministerial Decree number 37 year 2012.

8. Keller J, Layer P. Human pancreatic exocrine response to nutrients in health and diseases. Gut. 2005;54:1-28.

9. Widodo AD, Timan IS, Bardosono S, Winarta W, Prasetyo D, Firmansyah A. Variation in faecal elastase-1 reference levels in different regions of the world: an analysis and result from Indonesian children. ESPGHAN $51^{\text {st }}$ annual meeting, Geneva, 2018.

10. Widodo AD, Timan IS, Bardosono S, Winarta W, Prasetyo D, Firmansyah A. Panceratic exocrine insufficiency in malnourished children and those with persistent diarrhoea. Asia Pac J Clin Nutr. 2016;25(Suppl 1):S57-61.

11. The area under an ROC curve [cited 2018 May 21]. Available from http://gim.unmc.edu/dxtests/roc3.htm

12. Tardelli AC, Camargos PA, Penna FJ, Sarkis PF, Guimarães EV. Comparison of diagnostic methods for pancreatic insufficiency in infants with cystic fibrosis. J Ped Gastroenterol Nutr. 2013;56:178-81.

13. Bartels RH, Meyer SL, Stehmann TA, Bourdon C, Bandsma $\mathrm{RH}$, Voskuijl WP. Both exocrine pancreatic insufficiency and signs of pancreatic inflammation are prevalent in children with complicated severe acute malnutrition: an observational study. J Pediatr. 2016;174:165-70.

14. Simadibrata M, Hardjodisastro D, Rani AA. Pancreatic exocrine insufficiency in chronic diarrhea. The Indonesian Journal of Gastroenterology, Hepatology, and Digestive Endoscopy. 2005;6:4-8.

15. Walkowiak J, Nousia-Arvanitakis S, Cade A, Kashirskaya N, Piotrowski R, Strzykala K, et al. Fecal elastase-1 cut-off levels in the assessment of exocrine pancreatic function in cystic fibrosis. J Cyst Fibros. 2002;1(4):260-4.

16. Girish BN, Rajesh G, Vaidyanathan K, Balakrishnan V. Fecal elastase 1 and acid steatocrit estimation in chronic pancreatitis. Indian J Gastroenterol. 2009;28:201-5.

17. Amann ST, Josephson SA, Toskes PP. Acid steatocrit: a simple, rapid gravimetric method to determine steatorrhea. Am J Gastroenterol. 1997;92:2280-4.

18. Tran M, Forget P, Van den Neucker A, Strik J, van Kreel B, Kuijten R. The acid steatocrit: a much improved method. J Pediatr Gastroenterol Nutr. 1994;19:299-303.

19. Hammer HF. Pancreatic exocrine insufficiency: diagnostic evaluation and replacement therapy with pancreatic enzymes. Dig Dis. 2010;28:339-43. 